\title{
Mortality Rate and Years of Life Lost Due to Prostate Cancer in Yazd Province, Iran A 10 -year study
}

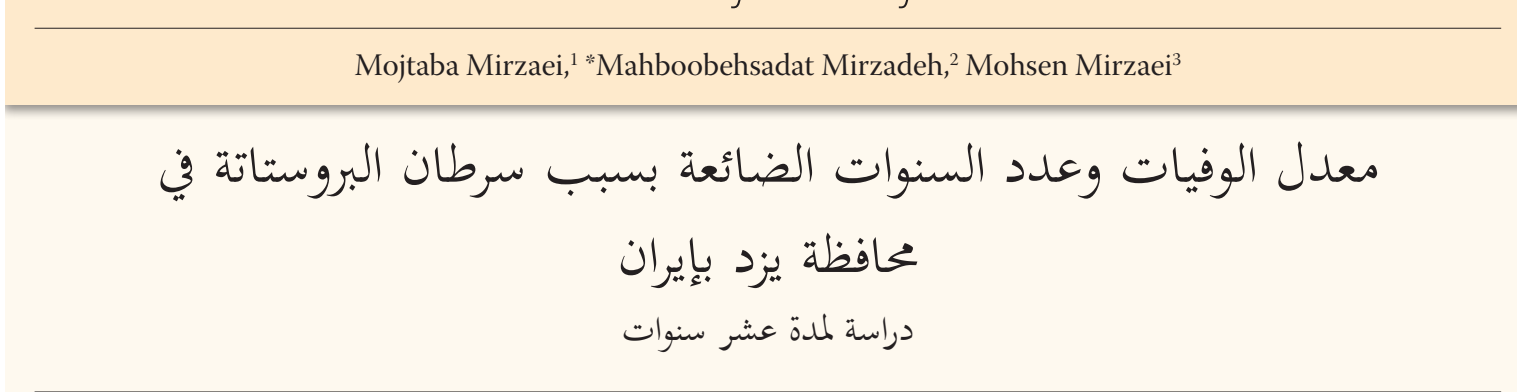

$$
\text { مجتبى ميرزائى، محبويه السادات ميرزاده، محسن ميرزائى }
$$

ABSTRACT: Objectives: Prostate cancer is a leading cause of cancer-related deaths. The number of deaths and years of life lost (YLL) due to a disease can be used to monitor health status, assess healthcare needs and determine the prioritisation and allocation of health resources within a population; in addition, the latter calculation can serve as a baseline indicator of premature mortality. This study aimed to measure prostate cancer-related mortality and YLL in Yazd Province, Iran. Methods: This study included all prostate cancer-related deaths in Yazd Province reported between March 2001 and March 2010. Mortality data were obtained from a provincial death registration system which integrates data from different sources. YLL was calculated based on an individual's age at death and their life expectancy according to age group. Results: During the study period, prostate cancer was the fourth most common fatal cancer among men, resulting in 324 deaths or $10.0 \%$ of all cancer-related deaths. The crude mortality rate per 100,000 individuals increased from 4.7 in 2001 to 8.8 in 2010. Premature deaths caused 1,358.7 YLL and the YLL caused by prostate cancer deaths more than doubled from 94.7 in 2001 to 196.5 in 2010. Conclusion: Due to changes in population structure, it is likely that the burden of prostate cancer will continue to increase in Yazd Province. As such, it is necessary that the national health system implements screening programmes and improves public awareness of prostate cancer-associated risk factors.

Keywords: Prostate Cancer; Years of Potential Life Lost; Mortality; Health Status Indicators; Iran.

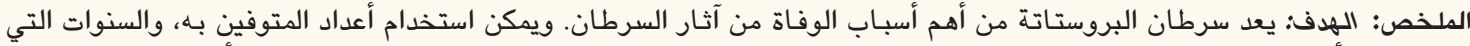

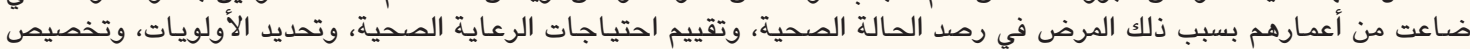

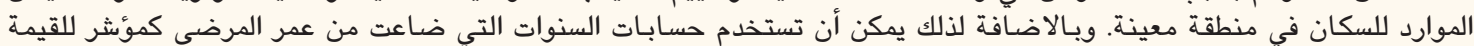

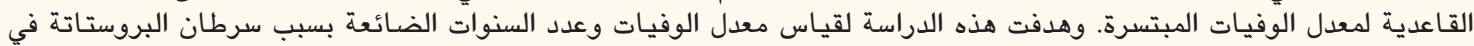

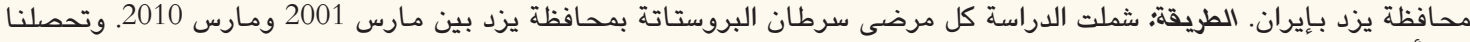

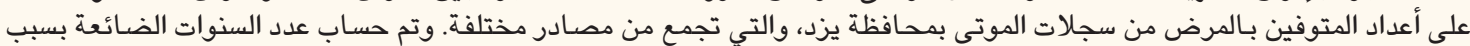

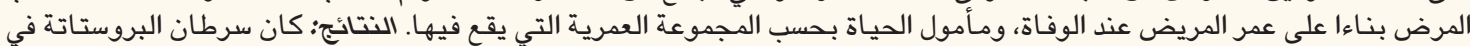

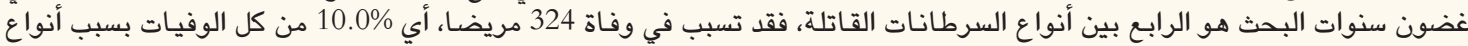

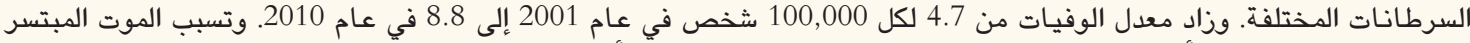

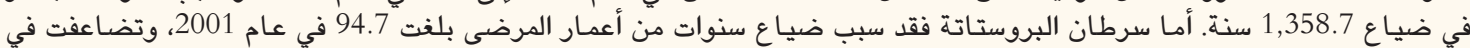

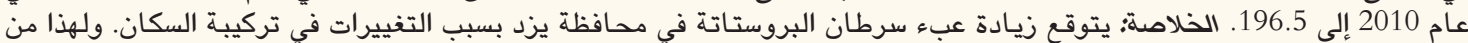

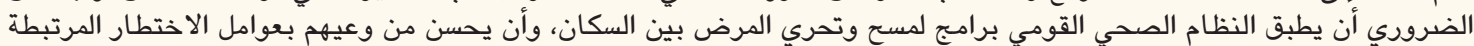
بسرطان البروستاتة.

الكلمات المفتاحية: سرطان البروستاتة؛ سنوات الحياة الهحتملة المفقودة؛ الوفيات؛ مؤشرات الحالة الصحية؛ إيران.

\section{ADVANCES IN KNOWLEDGE}

This study found that both the prostate cancer-related mortality rate and years of life lost due to prostate cancer increased over a 10-year period in Yazd Province, Iran.

\section{Application to Patient Care}

The findings of this study have implications for modifying on-going cancer screening programmes, prioritising health intervention programmes and integrating prostate cancer screening within the national health system in Iran. 
C ANCER is a LEADING CAUSE of MORTALity and years of life lost (YLL) worldwide; by 2050, the incidence of cancer in developing countries is forecast to increase by $45 \% .{ }^{1}$ Due to the high fatality rate of most cancers, YLL account for $90 \%$ of the burden of the disease and can therefore help policy-makers to prioritise health problems and design health interventions. ${ }^{2-4}$ The calculation of trends in cause-specific mortality can also help to indicate the effectiveness of healthcare programmes and the role of environmental risk factors in disease incidence and management. ${ }^{5}$

In 2012, approximately 1.1 million men worldwide were diagnosed with prostate cancer, making it the second most common cancer among men, equivalent to $15 \%$ of all male cancers. ${ }^{6}$ The incidence of this disease varies widely by geographical region, from 4.5 and 10.5 cases per 100,000 individuals in South Central and Eastern Asia, respectively, to 111.6 cases per 100,000 individuals in New Zealand and Australia. ${ }^{6}$ Of all new cases of prostate cancer in 2012, approximately $70 \%$ were reported from developed countries. ${ }^{6,7}$ Apart from the role of screening, this variation may be due to lifestyle, dietary, environmental and genetic differences. ${ }^{8}$ Nevertheless, while prostate cancer mortality in Western countries has reduced due to early diagnosis and treatment, the burden of prostate cancer is still growing in many developing countries, including Iran. ${ }^{9-14}$

In Iran, cancer is the third leading cause of mortality after cardiovascular disease and accidents, while prostate cancer is the third most common cancer and the eighth leading cause of mortality. ${ }^{13}$ However, trends in prostate cancer-related mortality have not been reliably measured in different regions within the country. Therefore, this study aimed to determine the burden and trends of prostate cancer-related mortality over a 10-year period in Yazd Province, a region at the geographic centre of Iran. In addition, the impact of premature deaths due to prostate cancer was quantified by calculating YLL due to the disease.

\section{Methods}

This study included all deaths due to malignant neoplasms of the prostate reported in Yazd Province between March 2001 and March 2010. Mortality data were obtained from the national death registration system in Iran which consists of information reported by physicians, healthcare institutions and cemeteries. Trained physicians at various institutions in Iran first report and code causes of death according to national protocols and the International Classification of Diseases; thereafter, hospitals, local health centres and cemeteries report these data monthly to a death registry committee. ${ }^{15}$ These reports are then matched and compared with data from the National Organization for Civil Registration and the Forensic Medicine Department. For the purposes of the study, duplicate death reports as determined based on similarities in the names of fathers, times of death and national identification numbers were excluded. When a garbage code or incomplete report was found, the researchers tried to retrieve the correct information via telephone interview with the responsible physician. This protocol was similarly used to obtain data for other causes of death.

Total population estimates in Yazd Province were calculated using information from health centre databases and national census data from 1996-2011 for which annual population growth was estimated exponentially. ${ }^{16}$ As such, the population of Yazd Province was set at 900,964 in 2001 and 1,056,638 in 2010, with the proportion of elderly individuals increasing from $8.3 \%$ to $9.1 \%$, respectively. Estimated demographic data for each year were used to calculate the indices for that specific year. Subsequently, the mortality rate from prostate cancer per 100,000 individuals, percentage of prostate cancer deaths out of all cancer deaths and YLL due to prostate cancer were calculated. The formula used to calculate YLL was determined as follows: ${ }^{17,18}$

YLL $=N C e^{(r a)} /(\beta+r)^{2}\left[e^{-(\beta+r)(L+a)}[-(\beta+r)\right.$ $\left.(L+a)-1]-e^{-(\beta+r) a}[-(\beta+r) a-1]\right]$

where $\mathrm{N}$ is the number of deaths within a certain age group and gender, $\mathrm{L}$ is the standard life expectancy of the deceased according to age group and gender, $r$ is a discount rate of $0.03, \beta$ is an age weight of $0.04, C$ is an age weight correction factor of 0.165 , a is the age at death and e is Euler's constant which is approximately equal to 2.71828. The average YLL (AYLL), which indicates how many more years a person would have lived had they not died prematurely, was calculated by dividing the total YLL by the total number of prostate cancer deaths annually.

Analysis of the data was performed using a YLL template developed by the World Health Organization in an Excel spreadsheet, Version 2007 (Microsoft Corp., Redmond, Washington, USA). ${ }^{17}$ A Chi-squared test was used to compare annual mortality rates. A $P$ value of $<0.05$ was considered statistically significant. The protocol of this study was reviewed and approved by the Ethics Committee of the Shahid Sadoughi University of Medical Sciences, Yazd Province. All aspects of the study were conducted in accordance with the ethical codes of the university and only anonymous secondary data were utilised for the analysis. 


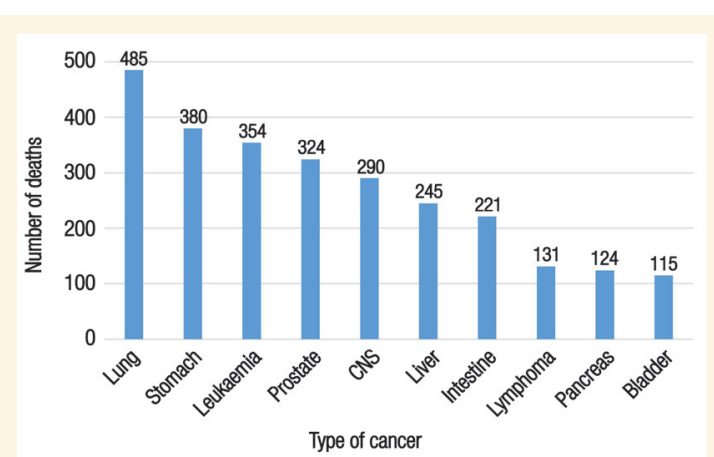

Figure 1: The ten leading causes of male cancer-related deaths between 2001-2010 in Yazd Province, Iran $(\mathrm{N}=2,669)$.

CNS = central nervous system

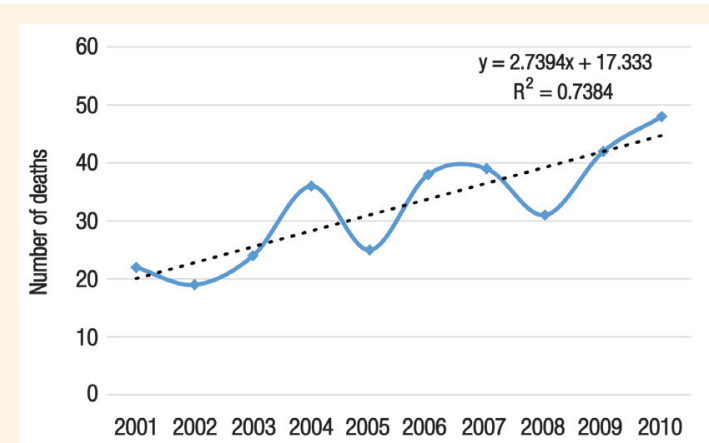

Figure 2: Trend in the number of prostate cancer-related deaths among deaths reported between 2001-2010 in Yazd Province, Iran $(\mathrm{N}=324)$.

Table 1: Prostate cancer-related mortality by age group among deaths reported between 2001-2010 in Yazd Province, Iran $(\mathrm{N}=324)$

\begin{tabular}{|lccc|}
\hline $\begin{array}{l}\text { Age group } \\
\text { in years }\end{array}$ & $\begin{array}{c}\text { Number } \\
\text { of } \\
\text { deaths }\end{array}$ & $\begin{array}{c}\text { Mortality rate } \\
\text { per 100,000 } \\
\text { individuals }\end{array}$ & Percentage $^{*}$ \\
\hline $30-49$ & 2 & 0.2 & 0.5 \\
$50-59$ & 12 & 3.7 & 3.2 \\
$60-69$ & 26 & 12.4 & 4.6 \\
$70-79$ & 133 & 87.0 & 13.6 \\
$\geq 80$ & 151 & 249.5 & 21.8 \\
\hline
\end{tabular}

*Percentage of prostate cancer deaths out of all cancer deaths.

\section{Results}

According to mortality data, a total of 324 deaths due to prostate cancer were reported in Yazd Province between 2001 and 2010. Prostate cancer was the fourth leading fatal cancer among men [Figure 1], accounting for $10.0 \%$ of all male cancer-related deaths. The total number of annual deaths due to prostate cancer increased significantly over the 10-year study period $(P<0.05)$ [Figure 2]. The mean age of the victims was 78 years (95\% confidence interval: $77-79$ years) and mean age did not differ significantly according to year
$(P>0.05)$. The majority of deaths occurred among men aged 70 years or older (87.7\%) [Table 1], although the youngest victim was only 33 years old. The mortality rate per 100,000 individuals increased from 4.7 in 2001 to 8.8 in 2010. The total YLL was 1,358.7 years and the overall AYLL was 4.2 years over the study period. The annual YLL more than doubled during the study period from 94.7 years in 2001 to 196.5 years in 2010 [Table 2].

\section{Discussion}

In the current study, the prostate cancer-related mortality rate per 100,000 individuals in Yazd Province increased from 4.7 in 2001 to 8.8 in 2010. A similar increasing trend has been reported in another study from Iran, although the annual mortality rates were comparatively lower (0.63 in 1995 to 5.49 in 2004). ${ }^{19}$ This difference highlights the likelihood of regional differences within the country with regards to the incidence and mortality of this type of cancer. ${ }^{13,19-21}$ Research conducted in other Iranian provinces has also shown wide variation in the incidence of prostate cancer, ranging from 3.2 to 16.0 cases per 100,000 individuals. ${ }^{22}$ Furthermore, the incidence of prostate cancer directly correlates with age and is rarely diagnosed among men under 50 years old; as such, the rate of mortality due to prostate cancer increases correspondingly with age. ${ }^{23}$ As a higher percentage of the population in Yazd Province is elderly in comparison to the rest of Iran, this may also explain the higher incidence and mortality rates observed in the current study. ${ }^{24}$ In general, YLL due to prostate cancer are lower on average compared to other cancers; however, within elderly populations, prostate cancer significantly contributes to total YLL. ${ }^{4}$

Currently, the incidence of prostate cancer remains higher in developed rather than developing countries. ${ }^{14}$ Nevertheless, although prostate cancerrelated mortality varies widely throughout the world, there is an increasing trend in prostate cancer-related mortality in less developed countries in contrast to Western countries. ${ }^{14}$ In 2012, prostate cancer-related mortality rates in Asian countries ranged from 0.7 and 1.2 per 100,000 individuals in Bhutan and Nepal to 17.1 and 22.8 per 100,000 individuals in Turkey and Lebanon, respectively. In Iran, the prostate cancer-related mortality rate has been reported to be 6 per 100,000 individuals. ${ }^{13}$ Differences in mortality between various countries, specifically in comparison to incidence, may be due to variations in the implementation of screening programmes and the availability of better diagnostic resources and treatment facilities. ${ }^{25}$ In addition, the effect of ethnic and genetic 
Table 2: Mortality and years of life lost due to prostate cancer among deaths reported between 2001-2010 in Yazd Province, Iran $(\mathrm{N}=324)$

$\begin{array}{lcccccccccc} & \mathbf{2 0 0 1} & \mathbf{2 0 0 2} & \mathbf{2 0 0 3} & \mathbf{2 0 0 4} & \mathbf{2 0 0 5} & \mathbf{2 0 0 6} & \mathbf{2 0 0 7} & \mathbf{2 0 0 8} & \mathbf{2 0 0 9} & \mathbf{2 0 1 0} \\ \text { Number of deaths } & 22 & 19 & 24 & 36 & 25 & 38 & 39 & 31 & 42 & 48 \\ \begin{array}{l}\text { Mortality rate per } \\ \mathbf{1 0 0 , 0 0 0 ~ i n d i v i d u a l s ~}\end{array} & 4.7 & 4.0 & 4.9 & 7.3 & 5.0 & 7.3 & 7.5 & 5.9 & 7.8 & 8.8 \\ \text { YLL } & 94.7 & 68 & 102.6 & 159.1 & 115.1 & 172.8 & 133.6 & 133.4 & 182.9 & 196.5 \\ \text { Percentage* } & 9.6 & 7.6 & 8.7 & 11.4 & 7.7 & 11.5 & 9.8 & 8.6 & 10.8 & 13.0\end{array}$

$Y L L=$ years of life lost.

*Percentage of prostate cancer deaths out of all cancer deaths.

variations on the incidence of prostate cancer has not yet been well determined. ${ }^{26,27}$ These variations may explain differences in the rate of deaths reported in Yazd Province as compared to other regions in Iran.

In the current study, the majority of deaths from prostate cancer occurred among those aged 70 years or older, which is consistent with the findings of other studies worldwide, indicating that age is one of the most important risk factors for prostate cancer. ${ }^{28,29}$ After the age of 50 years old, the lifetime risk of developing evidence of histological prostate cancer-related changes is estimated to be $42 \%{ }^{28}$ Moreover, according to research performed on autopsy samples, the prevalence of prostate cancer doubles approximately every 14 years. ${ }^{29}$ The combined effect of increased life expectancy and a growing elderly population underscores the importance of management strategies for prevalent diseases such as prostate cancer. Therefore, the increasing rate of prostate cancer-related mortality in Iran can be prevented through the development of additional screening programmes targeting the elderly in order to provide early diagnosis and care, specifically in provinces with a higher percentage of elderly and middle-aged people.

Nevertheless, it is possible that a greater number of younger people may be diagnosed with prostate cancer if they are provided with easier access to screening and diagnostic tests. Both lifestyle and dietary habits play a role in the pathogenesis of prostate cancer. ${ }^{30} \mathrm{~A}$ diet rich in red meat and smoking are risk factors for prostate cancer, whereas the consumption of tomatoes and participating in physical activity are potential preventative factors. ${ }^{31,32}$ A previous study found that $75.7 \%$ of elderly men in Yazd Province consumed red meat twice or more per week and $28.2 \%$ engaged only in low levels of physical activity; this may therefore explain the higher than average rates of prostate cancer in Yazd Province. ${ }^{33}$ However, establishing a definitive correlation between these factors would require further and more specific research.
The reported incidence and prevalence of prostate cancer is directly correlated with diagnostic measures; as such, the number of undiagnosed and non-reported cases should be considered when comparing prostate cancer incidence, prevalence and mortality rates. For example, many elderly individuals may die from other causes before showing signs of prostate cancer. ${ }^{34}$ Moreover, in addition to the introduction of the prostate-specific antigen (PSA) test, other changes in diagnostic and therapeutic methods may play a role in observed variations in prostate cancer incidence. Accordingly, rises in the diagnosis of prostate cancer have been linked to greater use of transurethral resections for benign prostate hyperplasia (BPH), as the surgery involves sampling and pathological assessment of the prostate. On the other hand, the use of $\alpha$-blockers and 5- $\alpha$-reductase for BPH treatment decreases the frequency of tissue sampling and may subsequently cause a reduction in reported incidence rates. ${ }^{35}$ Researchers disagree about the effectiveness of PSA screening in reducing prostate cancer-related mortality rates; while some studies propose this test as a noninvasive, easy-to-use, early screening tool in the general population, other studies have recommended PSA testing only for those at a high risk for the disease. ${ }^{36-38} \mathrm{An}$ algorithm has been suggested to identify high-risk patients based on their family history, digital rectal examination results and ethnicity. ${ }^{39}$

In the current study, while the overall mortality trend was found to have increased over the study period, there was a reduction in certain years, perhaps due to inconsistencies in the data collection. Temporarily rising trends may be due to the improved reporting and registration of deaths. Unfortunately, the specific diagnostic and treatment modalities offered to the patients involved in the current study prior to their deaths were not investigated. Therefore, further studies are required to determine whether the increased mortality was treatment-related or due to a lack of comprehensive screening. The current study 
was also subject to other limitations. First, the data obtained originated from a death registry based on death records, so the effect of spatial and temporal variations in diagnostic approaches on the incidence of prostate cancer was not evaluated. Second, telephone interviews with responsible physicians were undertaken only in cases of missing data or garbage codes. Thus, the researchers were unable to determine potential mistakes in diagnosis or reporting. Finally, postmortem examinations to confirm prostate cancer diagnoses were performed only in certain cases based on the decision of the primary physician.

\section{Conclusion}

Overall, there was an increasing trend in mortality rate and YLL due to prostate cancer in Yazd Province between 2001-2010. Moreover, the incidence of prostate cancer is expected to rise further in the near future due to increasing life expectancy. As such, the national healthcare system in Iran should develop specifically targeted plans for the prevention and management of various diseases, particularly those more prevalent among the elderly, such as prostate cancer. Early prostate cancer screening programmes should be developed and healthy diet and lifestyle choices should be promoted among the general population. However, in order to implement these measures successfully, further studies are needed to investigate the effectiveness of various methods for reversing the rising trend of prostate cancer.

\section{CONFLICT OF INTEREST}

The authors declare no conflicts of interest.

\section{FUNDING}

No funding was received for this study.

\section{References}

1. Pakzad R, Rafiemanesh H, Ghoncheh M, Sarmad A, Salehiniya H, Hosseini S, et al. Prostate cancer in Iran: Trends in incidence and morphological and epidemiological characteristics. Asian Pac J Cancer Prev 2016; 17:839-43. doi: 10.7314/APJCP.2016. 17.2.839.

2. Burnet NG, Jefferies SJ, Benson RJ, Hunt DP, Treasure FP. Years of life lost (YLL) from cancer is an important measure of population burden-and should be considered when allocating research funds. Br J Cancer 2005; 92:241-5. doi: 10.1038/sj. bjc. 6602321

3. Aragón TJ, Lichtensztajn DY, Katcher BS, Reiter R, Katz MH. Calculating expected years of life lost for assessing local ethnic disparities in causes of premature death. BMC Public Health 2008; 8:116. doi: 10.1186/1471-2458-8-116.

4. Naghavi M, Abolhassani F, Pourmalek F, Lakeh M, Jafari N, Vaseghi S, et al. The burden of disease and injury in Iran 2003. Popul Health Metr 2009; 7:9. doi: 10.1186/1478-7954-7-9.
5. Carter AJ, Nguyen CN. A comparison of cancer burden and research spending reveals discrepancies in the distribution of research funding. BMC Public Health 2012; 12:526. doi: 10.1186/1471-2458-12-526.

6. International Agency for Research on Cancer, World Health Organization. Prostate cancer estimated incidence, mortality and prevalence worldwide in 2012. From: http://globocan. iarc.fr/old/FactSheets/cancers/prostate-new.asp Accessed: Jul 2017.

7. Center MM, Jemal A, Lortet-Tieulent J, Ward E, Ferlay J, Brawley $\mathrm{O}$, et al. International variation in prostate cancer incidence and mortality rates. Eur Urol 2012; 61:1079-92. doi: 10.1016/j.eururo.2012.02.054.

8. Zahir ST, Nazemian MR, Zand S, Zare S. Survival of patients with prostate cancer in Yazd, Iran. Asian Pac J Cancer Prev 2014; 15:883-6. doi: 10.7314/APJCP.2014.15.2.883.

9. Rafiemanesh H, Rajaei-Behbahani N, Khani Y, Hosseini S, Pournamdar Z, Mohammadian-Hafshejani A, et al. Incidence trend and epidemiology of common cancers in the center of Iran. Glob J Health Sci 2016; 8:146-55. doi: 10.5539/gjhs. v8n3p146.

10. Sadjadi A, Nooraie M, Ghorbani A, Alimohammadian M, Zahedi MJ, Darvish-Moghadam S, et al. The incidence of prostate cancer in Iran: Results of a population-based cancer registry. Arch Iran Med 2007; 10:481-5. doi: 07104/AIM.0011.

11. Conceição MB, Boing AF, Peres KG. Time trends in prostate cancer mortality according to major geographic regions of Brazil: An analysis of three decades. Cad Saude Publica 2014; 30:559-66. doi: 10.1590/0102-311X00005813.

12. Jerez-Roig J, Souza DL, Medeiros PF, Barbosa IR, Curado MP, Costa IC, et al. Future burden of prostate cancer mortality in Brazil: A population-based study. Cad Saude Publica 2014; 30:2451-8. doi: 10.1590/0102-311X00007314.

13. Iran Ministry of Health and Medical Education Mortality profile in Iran (29 provinces) over the years 2006 to 2010. Tehran, Iran: Ministry of Health and Medical Education, 2013.

14. Torre LA, Bray F, Siegel RL, Ferlay J, Lortet-Tieulent J, Jemal A. Global cancer statistics, 2012. CA Cancer J Clin 2015; 65:87-108. doi: 10.3322/caac.21262.

15. Jafari N, Kabir MJ, Motlagh ME. Death registration system in I.R.Iran. Iran J Public Health 2009; 38:127-9.

16. Statistical Center of Iran. Population and housing censues: Census 2011. From: www.amar.org.ir/english/Census-2011 Accessed: Jul 2017.

17. World Health Organization; Mathers CD, Bernard C, Iburg KM, Inoue $M$, Fat DM, Shibuya K, et al. Global burden of disease in 2002: Data sources, methods and results. From: www.who.int/ healthinfo/paper54.pdf Acccessed: Jul 2017.

18. Ayatollahi SM, Hassanzadeh J, Ramezani AA. The burden of traffic accidents in South Khorasan Province, Iran in 2005. Iran J Epidemiol 2009; 4:51-7.

19. Fazeli Z, Pourhoseingholi MA, Vahedi M, Abadi A, Gholiizadeh S, Zali MR. Mortality rate of prostate cancer in Iranian men. Int J Anal Pharm Biomed Sci 2015; 4:70-5.

20. Rafiemanesh H, Enayatrad M, Salehiniya H. Epidemiology and trends of mortality from prostate cancer in Iran. J Isfahan Med Sch 2015; 33:515-21.

21. Esmaeimzadeh N, Salahi-Moghaddam A, Khoshdel AR. Geographic distribution of important cancers in Iran. Hormozgan Med J 2015; 19:73-82.

22. Mousavi SM. Toward prostate cancer early detection in Iran. Asian Pac J Cancer Prev 2009; 10:413-18.

23. Almasi A, Shamsi M, Eshrati B, Javaheri J, Alast SS, Ghasemi Z, et al. Epidemiology of prostate cancer in Markazi province in 2005-2010. J Neyshabur Univ Med Sci 2014; 2:1-8. 
24. Khosravi A, Alizadeh M, Torkashvand M, Aghaei N. Population ageing in IR Iran. From: http://catalog.ihsn.org/index.php/ citations/56631 Accessed: Jul 2017.

25. Stattin P, Carlsson S, Holmström B, Vickers A, Hugosson J Lilja $\mathrm{H}$, et al. Prostate cancer mortality in areas with high and low prostate cancer incidence. J Natl Cancer Inst 2014; 106:dju007. doi: 10.1093/jnci/dju007.

26. DeChello LM, Gregorio DI, Samociuk H. Race-specific geography of prostate cancer incidence. Int J Health Geogr 2006; 5:59. doi: 10.1186/1476-072X-5-59.

27. Cook MB, Rosenberg PS, McCarty FA, Wu M, King J, Eheman C, et al. Racial disparities in prostate cancer incidence rates by census division in the United States, 1999-2008. Prostate 2015; 75:758-63. doi: 10.1002/pros.22958.

28. Stangelberger A, Waldert M, Djavan B. Prostate cancer in elderly men. Rev Urol 2008; 10:111-19.

29. Bell KJ, Del Mar C, Wright G, Dickinson J, Glasziou P. Prevalence of incidental prostate cancer: A systematic review of autopsy studies. Int J Cancer 2015; 137:1749-57. doi: 10.1002/ ijc.29538.

30. Roshandel G, Boreiri M, Sadjadi A, Malekzadeh R. A diversity of cancer incidence and mortality in West Asian populations. Ann Glob Health 2014; 80:346-57. doi: 10.1016/j.aogh.2014.09.012.

31. Wolk A. Diet, lifestyle and risk of prostate cancer. Acta Oncol 2005; 44:277-81. doi: 10.1080/02841860510029572.

32. Huncharek M, Haddock KS, Reid R, Kupelnick B. Smoking as a risk factor for prostate cancer: A meta-analysis of 24 prospective cohort studies. Am J Public Health 2010; 100:693-701. doi: 10.2105/AJPH.2008.150508.
33. Bahrami D, Mirzaei M, Salehi-Abargouei A. Dietary behaviors of elderly people residing in central Iran: A preliminary report of Yazd Health Study. Elderly Health J 2016; 2:6-13.

34. Haas GP, Delongchamps N, Brawley OW, Wang CY, de la Roza G. The worldwide epidemiology of prostate cancer: Perspectives from autopsy studies. Can J Urol 2008; 15:3866-71.

35. Dickinson J, Shane A, Tonelli M, Connor Gorber S, Joffres M, Singh $\mathrm{H}$, et al. Trends in prostate cancer incidence and mortality in Canada during the era of prostate-specific antigen screening. CMAJ Open 2016; 4:E73-9. doi: 10.9778/cmajo.20140079.

36. Schröder FH, Hugosson J, Roobol MJ, Tammela TL, Ciatto S, Nelen V, et al. Screening and prostate-cancer mortality in a randomized European study. N Engl J Med 2009; 360:1320-8. doi: 10.1056/NEJMoa0810084.

37. Andriole GL, Crawford ED, Grubb RL 3rd, Buys SS, Chia D, Church TR, et al. Mortality results from a randomized prostatecancer screening trial. N Engl J Med 2009; 360:1310-19. doi: 10.1056/NEJMoa0810696.

38. Busato WF Jr, Almeida GL. Prostate cancer screening in Brazil: Should it be done or not? Int Braz J Urol 2016; 42:1069-80. doi: 10.1590/s1677-5538.ibju.2015.0709.

39. Carroll PR, Parsons JK, Andriole G, Bahnson RR, Castle EP, Catalona WJ, et al. NCCN guidelines insights: Prostate cancer early detection, version 2.2016. J Natl Compr Canc Netw 2016; 14:509-19. doi: 10.6004/jnccn.2016.0060. 